\title{
Iconicity in the speech of children and adults
}

\author{
Lynn K. Perry ${ }^{1}$ | Marcus Perlman ${ }^{2}$ | Bodo Winter ${ }^{3}$ | Dominic W. Massaro ${ }^{4}$ | \\ Gary Lupyan ${ }^{5}$
}

${ }^{1}$ Department of Psychology, University of Miami, Coral Gables, Florida, USA

${ }^{2}$ Language and Cognition Group, Max Planck Institute for Psycholinguistics, Nijmegen, The Netherlands

${ }^{3}$ Department of English Language and Literature, University of Birmingham, UK

${ }^{4}$ Department of Psychology, University of California Santa Cruz, USA

${ }^{5}$ Department of Psychology, University of Wisconsin Madison, USA

\section{Correspondence}

Lynn K. Perry, 5665 Ponce De Leon Blvd. Department of Psychology, University of Miami, Coral Gables, FL 33124, USA.

Email: lkperry@miami.edu

\begin{abstract}
Iconicity - the correspondence between form and meaning - may help young children learn to use new words. Early-learned words are higher in iconicity than later learned words. However, it remains unclear what role iconicity may play in actual language use. Here, we ask whether iconicity relates not just to the age at which words are acquired, but also to how frequently children and adults use the words in their speech. If iconicity serves to bootstrap word learning, then we would expect that children should say highly iconic words more frequently than less iconic words, especially early in development. We would also expect adults to use iconic words more often when speaking to children than to other adults. We examined the relationship between frequency and iconicity for approximately 2000 English words. Replicating previous findings, we found that more iconic words are learned earlier. Moreover, we found that more iconic words tend to be used more by younger children, and adults use more iconic words when speaking to children than to other adults. Together, our results show that young children not only learn words rated high in iconicity earlier than words low in iconicity, but they also produce these words more frequently in conversation - a pattern that is reciprocated by adults when speaking with children. Thus, the earliest conversations of children are relatively higher in iconicity, suggesting that this iconicity scaffolds the production and comprehension of spoken language during early development.
\end{abstract}

\section{RESEARCH HIGHLIGHTS}

- We investigated the frequency and iconicity, or sound-meaning correspondence, of $\sim 2000$ words in children's and adults' speech.

- Early parent-child conversations are characterized by the frequent use of highly iconic words.

- Adult conversations with other adults are characterized by the frequent use of more arbitrary (less iconic) words.

- Children's speech becomes less iconic (and more adult-like) over development.

\section{1 | INTRODUCTION}

Word learning should be incredibly difficult. Children must often interpret the meaning of a new word in chaotic environments with numerous possibilities, such as being asked to get the 'cup' in the context of a cluttered kitchen. Even after understanding a word's meaning in some contexts, children must learn to generalize to new contexts and to produce the word on their own. And yet by the time the average child is 2.5 years old, she produces approximately 700 words and many more word combinations (Fenson et al., 1994) - all before she can even tie her own shoes. How do children solve such a difficult problem, and not only understand, but also produce, all these hundreds of words? One way children might gain an advantage is by making use of the iconicity of certain words, or the resemblance between the sound of a word and its meaning (e.g., the word 'slurp' sounds like the sound made when performing that action). In this paper, we examine the role of iconicity in language use, asking whether iconicity relates to the frequency of words in children's and adults' speech.

A growing number of studies demonstrate that adults and especially children can use iconicity as an aid to learn and generalize the 
meanings of new words. For example, Lupyan and Casasanto (2015) found that adult participants were better at learning to categorize two species of aliens with pointed or rounded heads when they were labeled with iconic names corresponding with their visual feature ('crelch' and 'foove', respectively). Other studies have shown that children can use iconicity to learn individual word-referent associations (Asano et al., 2015; Imai, Kita, Nagumo, \& Okada, 2008; Kantartzis, Imai, \& Kita, 2011; Maurer, Pathman, \& Mondloch, 2006). For example, when English-learning preschoolers were taught novel verbs following the iconic structure of Japanese mimetics (a special class of words that tend to be high in iconicity, e.g. Imai \& Kita, 2014), they were more accurate at generalizing the correct action to a novel agent than preschoolers taught with non-iconic verbs (Kantartzis et al., 2011). Even children as young as 14 months of age have shown a learning advantage for iconic words (Imai et al., 2015).

One way iconicity can help children learn new words is by constraining potential meanings of a word (Imai \& Kita, 2014; Perniss \& Vigliocco, 2014). Children's sensitivity to the relationship between a word's form and meaning may help them to interpret the meaning of a new word in ambiguous situations. The better a child is at identifying a word's meaning, the more accurately they will then be able to generalize that word to new instances and contexts, subsequently increasing their productions of the word in new contexts.

If iconicity facilitates early word learning, then the words of a language that are learned earliest by children should be most iconic. In addition to the high prevalence of onomatopoeia (e.g., 'moo', 'quack') in children's early vocabulary (e.g., Laing, 2014), recent analyses of English and Spanish (Perry, Perlman, \& Lupyan, 2015) and British Sign Language (Thompson, Vinson, Woll, \& Vigliocco, 2012) show that the earliest-learned words tend to be the most iconic. Perry and colleagues obtained native-speaker iconicity ratings for English vocabulary (Fenson et al., 1994) and Spanish vocabulary (JacksonMaldonado et al., 2003) from the respective MacArthur-Bates Communicative Developmental Inventory (MCDI) checklists, and examined whether these ratings predicted the proportion of children who produced each word at age 30 months. In both languages, they found that early-learned words, such as 'bubbles' and 'splash', tend to be rated higher in iconicity than later-acquired words, such as 'person' and 'bench'. The relationship between iconicity and age of acquisition held after accounting for other factors known to relate to age of acquisition, such as word length, word frequency, and concreteness. The relationship between iconicity and age of acquisition also remained highly significant after removing all onomatopoetic words from the analyses.

These results show that young children tend to learn words rated higher in iconicity earlier than words rated lower in iconicity. However, it remains unclear what role iconicity plays in actual language use. Does iconicity influence how often children or adults say different words? Theoretically, once a word is learned, it could be used equally often as other already-learned words. (Once a child learns their 100th word they may use it as readily as their 1st.) However, it is possible that even after a child has learned to produce a word, its usage continues to be driven by the word's iconicity.
Here, we examine the iconicity and frequency of words in children's and adults' speech. If, as we propose, iconicity supports word learning and production, then words high in iconicity ought to be more frequent in young children's speech than words low in iconicity. One reason early-acquired words might be more iconic than later-acquired words is that caregivers may adjust their language when speaking to children to facilitate comprehension. When speaking to adults, however, there would not be the same adjustment requirements. We therefore also expect highly iconic words to be more frequent in adults' speech to children than in their speech to other adults. Alternatively, it may turn out that there is no relationship between iconicity and frequency of words in children's and adults' speech. If so, it would suggest that iconicity, while perhaps helpful in initial acquisition, does not continue to play an active role in early communication and language use.

Here we collected iconicity ratings for approximately 2000 English words, and then compared these ratings to the frequency of the words in children's speech, adults' child-directed speech, and adults' adultdirected speech. By examining differences in iconicity in these different registers of speech, we shed light on the role of iconicity in word usage, and how it might scaffold the acquisition of spoken language during development.

\section{2 | METHODS}

\section{1 | Participants}

We recruited 1593 native English speakers residing in the United States via Amazon Mechanical Turk.

\subsection{Stimuli}

We collected iconicity ratings for 2117 English words, of which 592 were drawn from the MacArthur-Bates Developmental Inventory of Words and Sentences (MCDI), a normed list of the early productive vocabulary of 16-30-month-old toddlers learning American English (Fenson et al., 1994). For these words, we used ratings previously collected by Perry et al. (2015). The 1525 new words were selected to maximize coverage with relevant psycholinguistic datasets of age of acquisition and concreteness norms. ${ }^{1}$ Compound and homonymous words (e.g., tear) were excluded. We created four randomized orders of the complete list and broke each into sub-lists of 25-26 randomly selected words.

Age of acquisition ( $A \circ A)$ was approximated using adult ratings from Kuperman, Stadthagen-Gonzalez and Brysbaert (2012) comprising the most comprehensive English AoA norms. Adults' subjective AoA ratings have been shown to correlate highly with objective measures of children's vocabulary development (Gilhooly \& Gilhooly, 1980; Morrison, Chappell, \& Ellis, 1997; Pind, Jónsdóttir, Gissurardóttir, \& Jónsson, 2000). Given that Perry et al. (2015) previously found iconicity-related differences in a more objective measure of AoA data for a smaller number of words, our analysis of AoA constitutes an independent replication with an expanded dataset. As a measure of word concreteness, we used adult ratings from Brysbaert, Warriner, and Kuperman (2014). 


\section{3 | Procedure}

Iconicity was quantified following the procedure of Perry et al. (2015). As in the previous study, the instructions defined iconicity and provided participants with examples of what an iconic, arbitrary, and 'opposite' meaning for a word might be (see below). The specific examples for opposite and arbitrary were drawn from Hockett (1960) and Pinker and Bloom's (1990) respective arguments regarding the arbitrariness of language.

Some English words sound like what they mean. For example, SLURP sounds like the noise made when you perform this kind of drinking action. An example that does not relate to the sound of an action is TEENY, which sounds like something very small (compared to HUGE which sounds big). These words are iconic. You might be able to guess these words' meanings even if you did not know English. Words can also sound like the opposite of what they mean. For example, MICROORGANISM is a large word that means something very small. And WHALE is a small word that means something very large. And finally, many words are not iconic or opposite at all. For example there is nothing canine or feline sounding about the words DOG or CAT. These words are arbitrary. If you did not know English, you would not be able to guess the meanings of these words.

Participants then rated one word at a time, on a scale ranging from -5 (opposite) to 5 (iconic). The 0 point corresponded to words that are arbitrary. See Figure 1. Participants were asked to say each word aloud before making their judgment. Each participant was randomly assigned to one of the sub-lists and rated its 25-26 words (limited to prevent fatigue), resulting in at least 10 ratings per word.

\subsection{Analysis}

We conducted all analyses using R version 3.3.1. (R Core Team, 2014). The Ime4 package version 1.1.12 was used for mixed model analysis (Bates, Maechler, Bolker, \& Walker, 2015), and several other packages were used for processing the data. ${ }^{2}$ All data and analyses are publicly accessible via the following link: http://www.github.com/bodowinter/ iconicity_acquisition. Throughout our analyses, we use linear models or linear mixed effects models. In all cases, visual inspection of plots of residuals against fitted values and Q-Q plots revealed no obvious deviations from normality and homoscedasticity. Variance inflation factors were estimated using the package car version 2.0.26, (Fox \& Weisberg, 2011), and these revealed no problems with (multi-)collinearity. When fitting interactions, variables were centered (Schielzeth, 2010).

Our analysis is separated into two parts: First, we examined whether words high in iconicity are acquired earlier than words low in iconicity - testing whether we replicate earlier findings that used much smaller vocabulary lists (i.e., Perry et al., 2015). Second, we move beyond previous work, examining whether words high in iconicity are more frequent in children's speech than words low in iconicity and whether adults' speech to children is more iconic than their speech to other adults.

Because AoA is known to be influenced by a number of factors, we used multiple regression to control for a word's overall frequency (based on the spoken section of the American Nation Corpus), concreteness, and number of morphemes. We also examined the relationship between iconicity and 'systematicity' for these words, based on data from Monaghan, Shillcock, Christiansen, and Kirby (2014). 'Systematicity' quantifies the statistical regularity of language-specific sound-meaning pairings (e.g., knowing 'glitter' and 'glisten' could facilitate learning of 'glow'). This measure was shown to predict AoA (Monaghan et al., 2014), but Perry and colleagues (2015) found that iconicity predicts AoA above and beyond systematicity for the first words children learn. We therefore sought to replicate this finding for our expanded set of words. Because systematicity measures were only available for 965 of our 2117 words (Monaghan et al., 2014), we conducted a second analysis of AoA on the subset of words for which this measure is available.

We next examined the relationship between iconicity and word frequency in children and adults' speech. For children's frequency, we used data from CHILDES, which has complete production frequencies for each 3-month period between 12 and 69 months. ${ }^{3}$ Word-level production frequencies were analyzed. Because this analysis included multiple data points per word (i.e., frequency of a given word for 12-14-month-olds, for 15-17-month-olds, etc.), we used linear mixed effects models. Word was fitted as a random intercept with a random slope for the effect of age (quantifying by-word variation in age effects). Models were fitted with maximum likelihood, and $p$-values were estimated using likelihood ratio tests (analysis of deviance). Adults' child-directed production frequency ${ }^{4}$ (based on CHILDES data collapsed across child age) and adults' adult-directed frequency (based on the American National Corpus) were each analyzed using multiple regression (item-level analysis). In all analyses, we control for AoA, concreteness, number of morphemes, and frequency in other speech types (e.g., analysis of frequency in children's speech controls for frequency in adults' child-directed and adult-directed speech).

\section{3 | RESULTS}

\subsection{Age of acquisition}

The relationship between iconicity and AoA is shown in Figure 2 . Words rated higher in iconicity tend to be acquired earlier (see Table 1, M1 for regression results). As can be seen in Table 1, M2, the
FIGURE 1 A sample trial of the iconicity ratings task

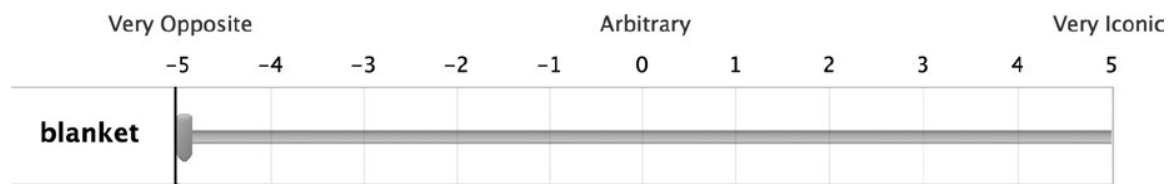




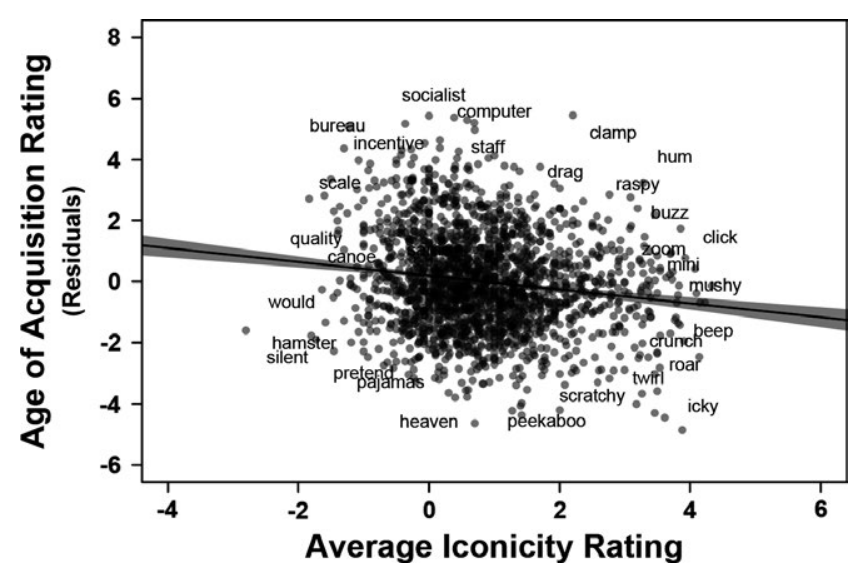

FIGURE 2 The effect of iconicity on age of acquisition (AoA) after controlling for overall word frequency, concreteness, and word length. Each dot corresponds to a word. The shaded region represents the $95 \%$ confidence region of the mean

TABLE 1 Results of each regression model used in analyses of AoA. M1-3 show the results of using iconicity to predict AoA. M4 shows the results of using systematicity to predict AoA. For each analysis, we controlled for the following covariates: concreteness, number of morphemes, and the frequency of words in adult-directed speech

\begin{tabular}{ll|}
\hline & Iconicity \\
\hline M1) Including all 2117 words & $b=-.35, t=-9.61, p<.0001$ \\
\hline $\begin{array}{l}\text { M2) Excluding onomatopoeia and } \\
\text { interjections; includes } 2090 \text { words }\end{array}$ & $b=-.34, t=-9.16, p<.0001$ \\
\hline $\begin{array}{l}\text { M3) Controlling for systematicity (only } \\
\text { including subset of } 930 \text { words for }\end{array}$ & $b=-.22, t=-4.76, p<.0001$ \\
which we have systematicity ratings; & \\
Monaghan et al., 2014) & \\
$\begin{array}{l}\text { M4) Predicting AoA from systematic- } \\
\text { ity; includes } 930 \text { words }\end{array}$ & $b=761.62, t=1.89, p=.059$ \\
\hline
\end{tabular}

relationship between iconicity and AoA was statistically reliable even after excluding all interjections and onomatopoetic forms (such as 'hush', 'buzz'). Iconicity was also a reliable predictor of AoA after controlling for systematicity in the subset of data for which both measures exist (Table 1, M3). The systematicity measure predicted AoA marginally (Table 1, M4). Together, these results replicate Perry et al.'s (2015) findings with a larger set of words that are acquired over a longer period of development. We next examined the relationship between iconicity ratings and frequency in children's and adult's speech.

\section{2 | Frequency in speech}

\subsection{1 | Children's speech}

As shown in Figure 3a, there was a positive relationship between a word's iconicity and its frequency in children's speech such that words high in iconicity tended to be more frequent than words low in iconicity (Table 2, M5). There was also an interaction between age and iconicity such that as children develop, words low in iconicity become more frequent than words high in iconicity. As shown in Figure 3a, younger children produce more iconic words more frequently than less iconic words, while older children produce more iconic words less frequently than less iconic words. The interaction between age and iconicity held after removing onomatopoetic words from the analyses (Table 2, M6). In all these analyses, we controlled for the overall number of words produced for a certain age. ${ }^{5}$

The analyses so far have focused on individual words - collapsing across speakers - to examine the relationship between iconicity and age in the use of these words. We next examine the relationship between iconicity and word usage over development for individual children. To allow this longitudinal analysis, we excluded data from several children of the CHILDES dataset (MacWhinney, 2000). We only included children over 12 months of age who produced at least 30 unique data points for at least five separate time points, resulting in 150 of the 323 children (see footnote 3 ). Using the iconicity ratings for each word, we calculated an average iconicity score for all words a child produced at each time point. These iconicity averages were computed in a frequency-weighted fashion: more frequent words contribute more to the estimated degree of iconicity in a child's vocabulary for a given month. For example, the child 'Betty' produced 34 different words at month 18 , with an average iconicity score of 1.07. At month 49 , she produced 129 different words with an average iconicity score of only 0.64 . Because the exact age-range varied from child to child, we normalized age to lie in the range between 0 and 1 to facilitate analysis (all results hold for non-normalized time series as well). A linear mixed effects model with time as a fixed effect and subject as random intercept (including by-subject time random slopes) revealed a significant effect of time. This relationship held after removing onomatopoeic words from the analysis, although only with marginal significance (Table 2, M7). The average iconicity fell from 0.64 for the first session with a child to an average of 0.56 for the last session of each child. A look at the random effects estimates (the best linear unbiased predictors) reveals that only 10 of 150 children had positive age slopes or increases in iconicity over time, meaning that $93 \%$ of all children in the sample decreased their use of words rated high in iconicity over time. Figure 4 shows how the relationship between frequency and iconicity changes over development for each child by showing the random effects of the mixed effects model, with each line representing an individual child. A generalized additive model (Wood, 2006; for use, see Winter \& Wieling, 2016) confirmed that a simple linear trend is appropriate (edf close to 1 ), with the average iconicity of words decreasing steadily with age.

\subsection{2 | Adults' speech}

As can be seen in Figure 3b, the relationship between iconicity and frequency in adults' speech depends on whether an adult is speaking to another adult or a child. In adult-directed speech, they tend to produce words rated lower in iconicity more frequently than words rated higher in iconicity. This result holds after removing onomatopoeic words from the analyses (Table 2, M8). Thus, conversations between adults tend to be characterized by the use of words lower in iconicity. 


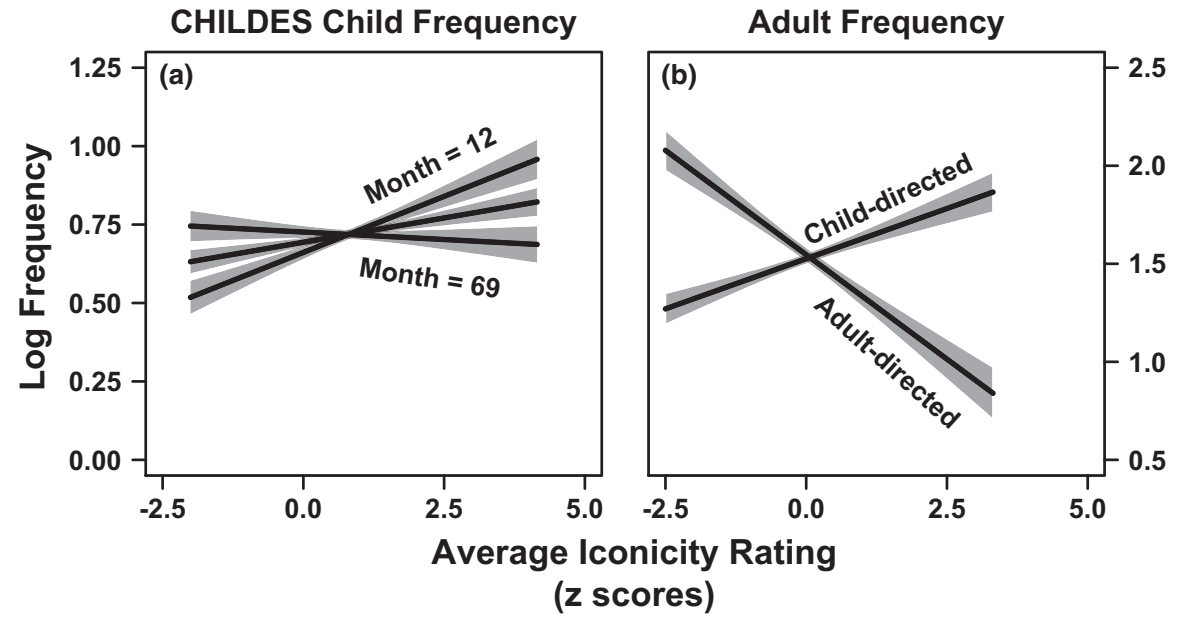

FIGURE 3 (a) Predicted production frequency for children, showing a reversal of the relationship from month 12 to month 69 . The middle line shows the relationship between iconicity and frequency for the median age ( 39 months), based on a linear mixed effects model. The analyses reported in the text model age as a continuous variable. (b) Predicted production frequency for adults in adult-directed and childdirected speech. Shaded regions represent the $95 \%$ confidence of the mean based on the corresponding statistical model. All visualizations incorporate controls for concreteness and word length. The child frequencies also incorporate controls for adult-directed and child-directed frequencies. The child-directed frequency also controls for adult-directed frequency

TABLE 2 Results of each regression model used in analyses of the relationship between iconicity and frequency. For each analysis, we controlled for the following covariates: concreteness, number of morphemes, AoA, and the frequency of words in the other two speech types from frequency of the speech type of interest

\begin{tabular}{|c|c|c|c|c|c|}
\hline & $\begin{array}{l}\text { M5) Frequency in } \\
\text { children's speech } \\
\text { (main effect of } \\
\text { iconicity) }\end{array}$ & $\begin{array}{l}\text { M6) Frequency in } \\
\text { children's speech } \\
\text { (interaction between } \\
\text { iconicity and age) }\end{array}$ & $\begin{array}{l}\text { M7) Frequency-weighted } \\
\text { iconicity in individual } \\
\text { children's speech } \\
\text { (main effect of age) }\end{array}$ & $\begin{array}{l}\text { M8) Frequency in } \\
\text { adults' adult- } \\
\text { directed speech }\end{array}$ & $\begin{array}{l}\text { M9) Frequency } \\
\text { in adults' } \\
\text { child-directed } \\
\text { speech }\end{array}$ \\
\hline $\begin{array}{l}\text { Including all words } \\
\qquad(N=2117)\end{array}$ & $\begin{array}{c}b=.03, t=4.55 \\
p<.0001\end{array}$ & $\begin{array}{c}b=-.25, t=6.58 \\
p<.0001\end{array}$ & $\begin{array}{c}b=-.1, t=4.72 \\
p<.0001\end{array}$ & $\begin{array}{c}b=-.21, t=10.85 \\
p<.0001\end{array}$ & $\begin{array}{c}b=.1, t=6.79 \\
p<.0001\end{array}$ \\
\hline $\begin{array}{l}\text { Excluding } \\
\text { onomatopoeia } \\
(N=2090)\end{array}$ & $\begin{array}{c}b=.03, t=3.92 \\
p<.0001\end{array}$ & $\begin{aligned} & b=-.02, t=5.57 \\
& p<.0001\end{aligned}$ & $\begin{array}{c}b=-.03, t=1.86 \\
p=.066\end{array}$ & $\begin{array}{c}b=-.21, t=0.46 \\
p<.0001\end{array}$ & $\begin{array}{c}b=.1, t=5.9 \\
p<.0001\end{array}$ \\
\hline
\end{tabular}

As can be seen in Figure 3b, however, adults' child-directed speech tends to be higher in iconicity. We found a positive association between iconicity and frequency in child-directed speech, such that words rated higher in iconicity appear more frequently than words rated lower in iconicity. This result held after removing onomatopoeic words from the analysis (Table 2, M9). Thus, as we had initially predicted, while overall adults tend to use words low in iconicity more frequently than those high in iconicity, when speaking to children they tend to use words of higher iconicity. Together with the results from children's own speech, this result suggests that early parent-child conversations tend to contain many high iconicity words.

\section{4 | DISCUSSION}

Our primary goal was to examine how the frequency of words in the speech of adults and children varies depending on iconicity. We found that the words used most frequently by young children tend to be more iconic: the higher a word is rated in iconicity, the more frequently it tends to be spoken. We found the same pattern in the child-directed speech of adults. In contrast, in adults' adult-directed speech, words lower in iconicity tended to be produced most frequently. Moreover, we found evidence that children's speech tends to change into this adult pattern of speech. Over development, children are increasingly likely to use less iconic (i.e., more arbitrary and opposite sounding) words. Together with our AoA results, these findings suggest that iconicity plays an important role in early language acquisition and use. However, over developmental time, iconicity becomes less important to children's ability to comprehend and produce words.

Perry and colleagues (2015) previously found that English and Spanish vocabularies were structured such that the earliest-learned words were higher in iconicity than later-learned words. These findings mirrored a pattern that has been independently observed for British Sign Language (Thompson et al., 2012; Vinson, Cormier, Denmark, Schembri, \& Vigliocco, 2008). Here we show that the effects of iconicity can be seen not only in word learning, but also in production. 


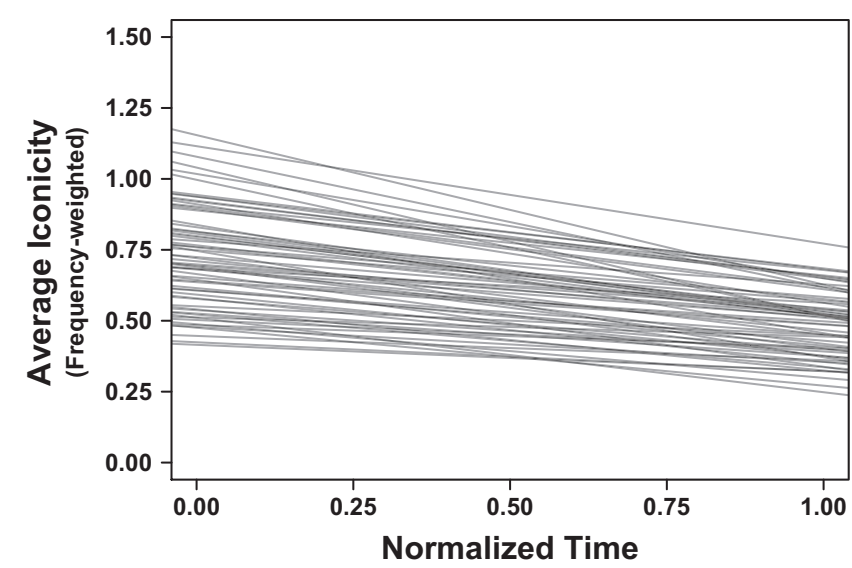

FIGURE 4 The best linear unbiased predictors (random effects estimates) for the longitudinal change of averaged iconicity over developmental time; each line corresponds to a single child; predictions come from a linear mixed effects regression; only predictions for the 66 children are displayed for which there were at least 10 different time points (for visualization purposes only, all 150 children were included in the actual analyses)

Children and their parents tend to use words rated higher in iconicity more frequently than words rated lower in iconicity, particularly in the language of the youngest children. Our results suggest the interesting possibility that iconicity might not only serve to facilitate word learning, but may also facilitate early communication by increasing understanding of language in context. This idea fits with previous work comparing the use of onomatopoeic words and non-linguistic sound effects by Japanese and English-speaking parents when speaking with children. Although Japanese speakers used more onomatopoeia overall, English speakers nevertheless used a small but noteworthy amount of iconic vocalizations - especially in the form of non-linguistic sound effects (Yoshida, 2012; and see Laing, Vihman, \& Keren-Portnoy, 2016). Our findings extend these results by demonstrating that the child-directed speech of English-speaking parents is enhanced by iconicity even outside of the special cases of onomatopoeic words and sound effects.

\subsection{How do some words become more iconic?}

Our results raise an interesting question for understanding the factors that shape the historical development of languages and their lexicons. We found that the English lexicon is structured such that early-learned and early high-frequency words are more iconic, and we have previously found that Spanish exhibits a similar pattern in the order of word acquisition (Perry et al., 2015). However, word forms are known to change considerably over the histories of languages: So how did these patterns come to exist in the current lexicons of English and Spanish?

One possibility is that children learn iconic words earlier because they are easier to learn, but the relationship between iconicity and AoA occurs independently of diachronic changes in the forms of words. That is, over historic time, words change to be more or less iconic for incidental reasons, and children are more inclined to learn and use those that happen to be more iconic.
Another possibility is that over the course of learning and use, words become more iconic. Perhaps adults modulate their pronunciation of words to have slightly more iconic forms, which are then learned by children. In support of this idea, adults have been found to exaggerate iconic properties of novel words in their child-directed speech (Nygaard, Herold, \& Namy, 2009). For example, when producing the novel word 'seebow' to mean 'big', adults increased the duration and amplitude and decreased the fundamental frequency relative to when it meant 'small'. Adults have also been found to modify their prosody in iconic ways outside of child-directed communication, such as when reading short stories out loud (Perlman, Clark, \& Johansson Falck, 2015; also see Shintel, Nusbaum, \& Okrent, 2006). These studies focused on prosodic properties, but phonetic features like vocal quality and voicing may be altered as well.

As a speculative example of how this process might operate to change words, consider the case of words with meanings related to 'small'. Across the world's languages, there is a bias for words meaning 'small' to contain the high front vowel /i/ (Blasi, Wichmann, Hammarström, Stadler, \& Christiansen, 2016). We know that speakers - and perhaps especially adults speaking with children - accentuate words for 'small' by raising their fundamental frequency (Nygaard et al., 2009; Perlman et al., 2015). It is also known that high vowels like /i/ tend to be articulated with a higher fundamental frequency than lower vowels (Whalen \& Levitt, 1995), and high front vowels, in particular, are characterized by a maximum difference between the frequencies of the second and first formants (Ohala, 1994). Thus, conceivably, when speakers produce an iconic rise in pitch for 'small' this could push their articulation of the word's vowel to be higher and more fronted. The raised pitch might also bias the perception of the vowel as higher and more fronted than it really is. Over generations, this iconic accentuation could drive changes in the phonology of the word - a push towards /i/ - as more iconic forms are picked up by children, and become fossilized in the lexicon. Interestingly, there is evidence that highly iconic words resist the sound changes that other words undergo, suggesting that once a form becomes iconic, it tends to stay that way across long historical periods of a language (Joseph, 1987; and see Perniss, Thompson, \& Vigliocco, 2010). Examining the extent to which iconic communication between parents and children might change the lexicon will be an important direction for future research.

\section{2 | Questions of directionality}

Another important, but still unanswered question is whether iconicity in parents' speech has a causal role in children's learning, or whether children's increased use of iconicity leads parents to increase their own use of iconicity. The current data support the proposal that iconicity actively facilitates language acquisition (Imai \& Kita, 2014; Perniss \& Vigliocco, 2014). Parents might be implicitly (or explicitly) aware of this learning advantage and hence use iconic words more often, helping their children to more easily comprehend and produce language. 
However, the corpus data we analyzed contained conversational transcriptions, but no measures of word learning and recognition. Thus, we are not yet able to assess the consequences that individual parents' and children's use of iconicity has on children's previous or subsequent language development. To answer such questions about the consequences of iconicity in speech, we would need to assess whether parents whose child-directed speech contains more iconicity have children who are better at word learning. For example, they may have faster rates of word recognition, or they may be able to learn a new word after fewer exposures. Examining the consequences of iconicity on learning would be an important step in finding a causal link between iconicity and acquisition.

\section{3 | Conclusions}

Our results show that young children learn iconic words earlier, and they also use iconic words more frequently - a pattern that is reciprocated by adults when speaking with children. As children develop, they increasingly learn words with more arbitrary forms and begin to use them increasingly often in conversation. That the earliest conversations of children are distinctly iconic suggests that iconicity scaffolds the production and comprehension of spoken language during early development. More generally, these findings support the emerging theory that many of the words of spoken languages are iconic in functionally significant ways, spanning language development, evolution, and online processing (Clark, 2016; Dingemanse, Blasi, Lupyan, Christiansen, \& Monaghan, 2015; Imai \& Kita, 2014; Lockwood \& Dingemanse, 2015; Lockwood, Hagoort, \& Dingemanse, 2016; Perlman \& Cain, 2014; Perniss \& Vigliocco, 2014). Far from being a fluke of isolated segments of the English lexicon, iconicity is systematically distributed across the early lexicon, and it appears to play an important role in early communication.

\section{ENDNOTES}

${ }^{1}$ Of our total list of 2117 English words normed for iconicity, 1980 words are also normed for AoA in Kuperman et al. (2012) ( 96\%) and 2126 words are also normed for concreteness in Brysbaert et al. (2014) ( 98\%). We selected words from these two lists pseudo-randomly, with the aim of having words represented on both lists and appearing in the CHILDES corpora.

${ }^{2}$ We used dplyr version 0.5 (Wickham \& Francois, 2015)., car 2.0.26 (Fox \& Weisberg, 2011), stringr verson 1.0.0 (Wickham, 2015), reshape 1.4.1 (Wickham, 2007), readr 1.0.0 (Wickham, Hester, \& Francois, 2016), mgcv 1.8.7 (Wood, 2006) and itsadug 2.2 (Van Rij, Wieling, Baayen, \& Van Rijn, 2016).

${ }^{3}$ Child frequencies were obtained from http://childfreq.sumsar.net/ (Baath, 2010). Our analysis of individual child frequencies includes data also taken from ChildFreq from the following 26 CHILDES corpora: Bates, Belfast, Bernstein, Bliss, Bloom70, Bloom73, Brown, Cornell, Cruttenden, Demetras1, Evans, Fletcher, Gleason, Howe, HSLLD, Kuczaj, Manchester, McCune, Post, Providence, Snow, Soderstrom, Suppes, Weist, Wells. This compiled data file is publically available at http://www.github.com/ bodowinter/iconicity_acquisition.

${ }^{4}$ Parental input frequencies are taken from http://childes.psy.cmu.edu/derived/, based on Ping Li's processing of the following CHILDES corpora:
Bates, Belfast, Bernstei, Bliss, Bloom, Brown, Clark, Cornell, Demetras, Fletcher, Gathercole, Hall, Higginso, Howe, Kuczaj, Macboys, Macros, Peters, Post, Sachs, Snow, Suppes, Valian, Vanhout, Vankleec, Warren, Wells.

${ }^{5}$ Iconicity was also reliably associated with word frequency when a relative measure (frequency of word $X$ divided by the total word count at age $Y$ ) was used as a dependent measure rather than raw word counts.

\section{REFERENCES}

Asano, M., Imai, M., Kita, S., Kitajo, K., Okada, H., \& Thierry, G. (2015). Sound symbolism scaffolds language development in preverbal infants. Cortex, 63, 196-205.

Baath, R. (2010). ChildFreq: An online tool to explore the word frequencies in child language.

Bates, D., Maechler, M., Bolker, B., \& Walker, S. (2015). Fitting linear mixedeffects models using Ime4. Journal of Statistical Software, 67, 1-48.

Blasi, D.E., Wichmann, S., Hammarström, H., Stadler, P.F., \& Christiansen, M.H. (2016). Sound-meaning association biases evidenced across thousands of languages. Proceedings of the National Academy of Sciences, USA, 113, 10818-10823.

Brysbaert, M., Warriner, A.B., \& Kuperman, V. (2014). Concreteness ratings for 40 thousand generally known English word lemmas. Behavior Research Methods, 46, 904-911.

Clark, H.H. (2016). Depicting as a method of communication. Psychological Review, 123, 324-347.

Dingemanse, M., Blasi, D.E., Lupyan, G., Christiansen, M.H., \& Monaghan, P. (2015). Arbitrariness, iconicity, and systematicity in language. Trends in Cognitive Sciences, 19, 603-615.

Fenson, L., Dale, P.S., Reznick, J.S., Bates, E., Thal, D.J., \& Pethick, S.J., ... \& Stiles, J. (1994). Variability in early communicative development. Monographs of the Society for Research in Child Development, 59, i-185. https://doi.org/10.2307/1166093

Fox, J., \& Weisberg, S. (2011). An R companion to applied regression (2nd edn.). Thousand Oaks, CA: Sage.

Gilhooly, K.J., \& Gilhooly, M.L.M. (1980). The validity of age-of-acquisition ratings. British Journal of Psychology, 71, 105-110.

Hockett, C.F. (1960). The origin of speech. Scientific American, 203, 88-96.

Imai, M., \& Kita, S. (2014). The sound symbolism bootstrapping hypothesis for language acquisition and language evolution. Philosophical Transactions of the Royal Society of London. Series B, Biological Sciences, 369, 20130298.

Imai, M., Kita, S., Nagumo, M., \& Okada, H. (2008). Sound symbolism facilitates early verb learning. Cognition, 109, 54-65.

Imai, M., Miyazaki, M., Yeung, H.H., Hidaka, S., Kantartzis, K., Okada, H., \& Kita, S. (2015). Sound symbolism facilitates word learning in 14-month-olds. PLoS ONE, 10, e0116494.

Jackson-Maldonado, D., Thal, D.J., Marchman, V.A., Newton, T., Fenson, L., \& Conboy, B. (2003). MacArthur Inventarios del Desarrollo de Habilidades Comunicativas: User's guide and technical manual. Baltimore, MD: Brookes.

Joseph, B.D. (1987). On the use of iconic elements in etymological investigation: Some case studies from Greek. Diachronica, 4, 1-26.

Kantartzis, K., Imai, M., \& Kita, S. (2011). Japanese sound-symbolism facilitates word learning in English-speaking children. Cognitive Science, 35, 575-586.

Kuperman, V., Stadthagen-Gonzalez, H., \& Brysbaert, M. (2012). Ageof-acquisition ratings for 30,000 English words. Behavior Research Methods, 44, 978-990.

Laing, C.E. (2014). A phonological analysis of onomatopoeia in early word production. First Language, 34, 387-405.

Laing, C.E., Vihman, M., \& Keren-Portnoy, T. (2016). How salient are onomatopoeia in the early input? A prosodic analysis of infantdirected speech. Journal of Child Language. https://doi.org/10.1017/ S0305000916000428 
Lockwood, G., \& Dingemanse, M. (2015). Iconicity in the lab: A review of behavioral, developmental, and neuroimaging research into soundsymbolism. Frontiers in Psychology, 6, 1246.

Lockwood, G., Hagoort, P., \& Dingemanse, M. (2016). How iconicity helps people learn new words: Neural correlates and individual differences in sound-symbolic bootstrapping. Collabra, 2, 7.

Lupyan, G., \& Casasanto, D. (2015). Meaningless words promote meaningful categorization. Language and Cognition, 7, 167-193.

MacWhinney, B. (2000). The CHILDES Project: Tools for analyzing talk (3rd edn.). Mahwah, NJ: Lawrence Erlbaum Associates.

Maurer, D., Pathman, T., \& Mondloch, C.J. (2006). The shape of boubas: Sound-shape correspondences in toddlers and adults. Developmental Science, 9, 316-322.

Monaghan, P., Shillcock, R.C., Christiansen, M.H., \& Kirby, S. (2014). How arbitrary is English?. Philosophical Transactions of the Royal Society of London Series B, Biological Sciences, 369, 20130299.

Morrison, C.M., Chappell, T.D., \& Ellis, A.W. (1997). Age of acquisition norms for a large set of object names and their relation to adult estimates and other variables. Quarterly Journal of Experimental Psychology Section A, 50, 528-559.

Nygaard, L.C., Herold, D.S., \& Namy, L.L. (2009). The semantics of prosody: Acoustic and perceptual evidence of prosodic correlates to word meaning. Cognitive Science, 33, 127-146.

Ohala, J.J. (1994). The frequency code underlies the sound-symbolic use of voice pitch. In J. Hinton, J. Nichols, \& J.J. Ohala (Eds.), Sound symbolism (pp. 325-347). Cambridge: Cambridge University Press.

Perlman, M., \& Cain, A.A. (2014). Iconicity in vocalization, comparisons with gesture, and implications for theories on the evolution of language. Gesture, 14, 320-350.

Perlman, M., Clark, N., \& Johansson Falck, M. (2015). Iconic prosody in story reading. Cognitive Science, 39, 1348-1368.

Perniss, P., Thompson, R., \& Vigliocco, G. (2010). Iconicity as a general property of language: Evidence from spoken and signed languages. Frontiers in Psychology, 1, 227.

Perniss, P., \& Vigliocco, G. (2014). The bridge of iconicity: From a world of experience to the experience of language. Philosophical Transactions of the Royal Society B: Biological Sciences, 369, 20130300.

Perry, L.K., Perlman, M., \& Lupyan, G. (2015). Iconicity in English and Spanish and its relation to lexical category and age of acquisition. PLoS ONE, 10, e0137147.

Pind, J., Jónsdóttir, H., Gissurardóttir, H., \& Jónsson, F. (2000). Icelandic norms for the Snodgrass and Vanderwart (1980) pictures: Name and image agreement, familiarity, and age of acquisition. Scandinavian Journal of Psychology, 41, 41-48.
Pinker, S., \& Bloom, P. (1990). Natural language and natural selection. Behavioral and Brain Sciences, 13, 707-727.

$R$ Core Team (2014). R: A language and environment for statistical computing. Vienna: R Foundation for Statistical Computing. Retrieved from http:// www.R-project.org/

Schielzeth, H. (2010). Simple means to improve the interpretability of regression coefficients. Methods in Ecology and Evolution, 1, 103-113.

Shintel, H., Nusbaum, H.C., \& Okrent, A. (2006). Analog acoustic expression in speech communication. Journal of Memory and Language, 55, 167-177.

Thompson, R.L., Vinson, D.P., Woll, B., \& Vigliocco, G. (2012). The road to language learning is iconic: Evidence from British Sign Language. Psychological Science, 23, 1443-1448.

Van Rij, J., Wieling, M., Baayen, R.H., \& Van Rijn, H. (2016). itsadug: Interpreting time series and autocorrelated data using GAMMs (Version 2.2).

Vinson, D.P., Cormier, K., Denmark, T., Schembri, A., \& Vigliocco, G. (2008). The British Sign Language (BSL) norms for age of acquisition, familiarity, and iconicity. Behavior Research Methods, 40, 1079-1087.

Whalen, D.H., \& Levitt, A.G. (1995). The universality of intrinsic F0 of vowels. Journal of Phonetics, 23, 349-366.

Wickham, H. (2007). Reshaping data with the reshape package. Journal of Statistical Software, 21, 1-20.

Wickham, H. (2015). stringr: Simple, consistent wrappers for common string operations (Version 1.0.0).

Wickham, H., \& Francois, R. (2015). dplyr: A grammar of data manipulation (Version 0.5).

Wickham, H., Hester, J., \& Francois, R. (2016). readr: Read tabular data (Version 1.0.0).

Winter, B., \& Wieling, M. (2016). How to analyze linguistic change using mixed models, Growth Curve Analysis and Generalized Additive Modeling. Journal of Language Evolution, 1, 7-18.

Wood, S.N. (2006). Generalized Additive Models: An introduction with R. Boca Raton, FL: Chapman and Hall/CRC.

Yoshida, H. (2012). A cross-linguistic study of sound symbolism in children's verb learning. Journal of Cognition and Development, 13, 232-265.

How to cite this article: Perry LK, Perlman M, Winter B, Massaro DW, Lupyan G. Iconicity in the speech of children and adults. Dev Sci. 2018;21:e12572. https://doi.org/10.1111/ desc.12572 